\title{
Application of ICME to Engineer Fatigue-Resistant Ni-Base Superalloys Microstructures
}

\author{
SAMMY TIN,${ }^{1,5}$ MARTIN DETROIS, ${ }^{1,4}$ JOHN ROTELLA, ${ }^{2}$ \\ and MICHAEL D. SANGID ${ }^{2,3}$
}

1.-Illinois Institute of Technology, 10 W. 32nd Street, Chicago, IL 60616, USA. 2.-School of Materials Engineering, Purdue University, 701 W. Stadium Ave., West Lafayette, IN 47907, USA. 3.-School of Aeronautics and Astronautics, Purdue University, $701 \mathrm{~W}$. Stadium Ave., West Lafayette, IN 47907, USA. 4.-Present address: National Energy Technology Laboratory/AECOM, 1450 Queen Ave. SW, Albany, OR 97321, USA. 5.—e-mail: tin@iit.edu

Critical rotating components used in the hot section of gas turbine engines are subject to cyclic loading conditions during operation, and the life of these structures is governed by their ability to resist fatigue. Since it is well known that microstructural parameters, such as grain size, can significantly influence the fatigue behavior of the material, the conventional processes involved with the manufacture of these structures are carefully controlled in an effort to engineer the resulting microstructure. For a commercial Ni-base superalloy, RR1000, the development of process models and deformation mechanism maps has enabled not only control of the resultant grain size but also the ability to tailor and manipulate the resulting grain boundary character distribution. The increased level of microstructural control was coupled with a physics-based fatigue model to form an integrated computational materials engineering framework that was used to guide the design of damage-tolerant microstructures. Simulations from a 3D crystal plasticity finite element model were used to identify microstructural features associated with strain localization during cyclic loading and to guide the design of polycrystalline microstructures optimized for fatigue resistance. Conventionally processed and grain boundary engineered forgings of a commercial Ni-based superalloy, RR1000, were produced to validate the design methodology. For nominally equivalent grain sizes, high-resolution strain maps generated via digital image correlation confirmed that the high density of twin boundaries in the grain boundary engineered material were desirable microstructural features as they contribute to limiting the overall length of persistent slip bands that often serve as precursors for the nucleation of fatigue cracks.

\section{INTRODUCTION}

Recent advancements in materials and manufacturing technologies have served as enabling technologies that have greatly benefited the aerospace industry. ${ }^{1,2}$ From commercial aircraft that are fabricated with composite fuselages to advanced gas turbine engines that utilize additively manufactured parts and innovative classes of advanced alloys, these changes have contributed to transformational gains in efficiency improvements and emissions reductions associated with the commercial aviation sector over the past few decades. Despite the development and integration of novel classes of materials and processes, the durability and life of these complex engineered systems is ultimately still limited by the fatigue behavior of the constituent components. ${ }^{3-5}$ Repeated cyclic loading and unloading of structural components gradually induces damage in the form of fatigue cracks to nucleate within the microstructure of the material. The nucleation and subsequent growth of these cracks is ultimately what governs the useful operating life of the structure and dictates the service intervals for reliable operation. 
In advanced gas turbine engines, Ni-base superalloys are widely used in the hot section of the engine as they exhibit an optimal balance of properties that are well suited to resist a combination of creep, fatigue, and corrosion at elevated temperatures. ${ }^{6,7}$ These properties are achieved through a combination of careful control of both the chemical composition and the processing route to manipulate and engineer the desired microstructure. For polycrystalline Ni-base superalloys, the microstructure of the material can potentially impact all of the major properties from creep and fatigue to oxidation and hot corrosion. The strength and creep resistance of Ni-base superalloys is largely dependent on the chemistry of the $\gamma^{\prime}$ precipitates as well as on their fraction and distribution within the microstructure. ${ }^{8}$ In polycrystalline Ni-base superalloys, the grain size also plays a significant role in determining the strength and creep resistance as grain boundary sliding and damage accumulation become operative mechanisms. As a result, optimizing the properties of new and existing Ni-base superalloys requires an understanding of both how the physics of deformation is affected by the microstructure as well as how to control the formation of microstructure via processing.

Integrated computational materials engineering (ICME) methodologies have gained in popularity in recent years and are now capable of serving as powerful tools that link multiple, traditionally discrete models together to provide a broader, more holistic understanding of the interdependencies between processing-microstructure-property relationships. Within the high-temperature structural materials community, ICME has made a substantial impact as a viable design tool as various successful case studies have been highlighted over the years. ${ }^{9,10}$ For example, based on accomplishments from the DARPA AIM program, turbine disk design engineers can now take advantage of heterogeneous or location-specific properties associated with differences in the $\gamma^{\prime}$ size and distribution stemming from differences in cooling rate from the postforging solution heat treatment. ${ }^{11,12}$ Another successful example was the Integrated Modeling for the Manufacture of Aerospace Disks (IMMAD) program that linked various process models for solidification, heat treatment, forging, and residual stresses together such that grain structure evolution could be tracked through the entire process from solidification to final forging. ${ }^{13,14}$ One major advantage associated with the ICME methodology is that once the framework for a particular process or material is established and validated, these models can be effectively exploited for a variety of optimization and parametric design studies.

In this particular investigation, an ICME framework was applied to "inversely" engineer a more robust and damage-tolerant microstructure populated with a high density of coherent twin boundaries (a low-energy variant of a $\Sigma 3$-type boundary) for a commercially used Ni-base superalloy, RR1000. An existing physics-based fatigue model was used to identify key microstructural features that affect the nucleation of fatigue cracks and contribute to the design of a microstructure optimized for fatigue resistance. ${ }^{15,16}$ This information was then used as a guide to develop microstructure-explicit constitutive models that could be used to obtain the designed microstructures via changes in the thermal-mechanical parameters. Small-scale forgings were produced and heat treated to validate the model predictions as both conventional and grain boundary engineered microstructures were produced. Finally, the deformation mechanisms and fatigue behavior of the engineered microstructures were assessed using high-resolution digital image correlation that generated strain maps relative to the microstructural features and validated the proposed approach. This article presents an overview of the methodologies used and successfully demonstrates how integrating process and performance models can contribute to enhanced design and manufacture of Ni-based superalloy forgings.

\section{PROCESS MODELS FOR ENGINEERING THE GRAIN BOUNDARY CHARACTER DISTRIBUTION}

Traditional grain boundary engineering (GBE) techniques have been employed over the years to improve various materials properties such as corrosion and the resistance to fatigue crack propagation. ${ }^{17}$ The process typically consists of steps of cold rolling followed by short time annealing, which results in the formation of annealing twins or $\Sigma 3$ boundaries. ${ }^{18,19}$ The iterative deformation/ annealing route allows for both the interaction of $\Sigma 3^{n}(n=1,2,3)$ boundaries and greater strain addition, thus, leading to further increases in twin fraction, the formation of incoherent twins, and/or triple junctions. Although GBE has proved its ability to increase select materials properties, the process has seen only limited commercial applications. This is evidently attributed to its deviation from standard industry practices. Forging of large gas turbine engine components cannot be performed at the low temperatures employed during GBE because of the likelihood of strain-induced cracking during deformation of high-strength Nibased superalloys. Furthermore, the iterative process would considerably increase the manufacturing time, while the short time thermal processing cycles would be demanding on the equipment. Overall, the final cost of the component would significantly increase even if the limitations associated with low-temperature forging could be overcome. Therefore, the traditional GBE techniques are not appropriate for the fabrication of large components for power generation applications. 


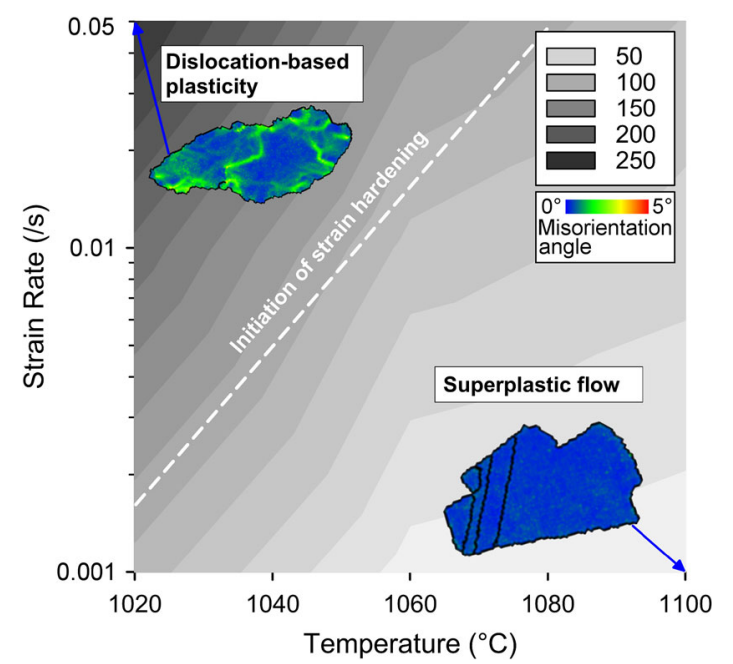

Fig. 1. Deformation mechanism map for RR1000 showing the maximum stress in $\mathrm{MPa}$ as a function of the deformation temperature and strain rate with example grains showing intragranular lattice misorientation for the samples deformed at $1020^{\circ} \mathrm{C}-0.05 \mathrm{~s}^{-1}$ and $1100^{\circ} \mathrm{C}-0.001 \mathrm{~s}^{-1}$.

In an effort to adapt the concept of GBE to industrial settings, a preliminary investigation was conducted to assess the possible use of conventional high-temperature isothermal forging as a replacement to cold rolling in GBE. Laboratory-scale isothermal compression using a Gleeble system was performed to observe the influence of the deformation parameters on the flow mechanisms and their effect on the formation of coherent twin boundaries. ${ }^{20,21} \mathrm{~A}$ deformation mechanisms map was developed for RR1000, represented in Fig. 1, which revealed the predominant flow mechanisms, namely, superplastic flow and dislocation-based plasticity. ${ }^{20,21}$ Modest changes in the isothermal deformation parameters were found sufficient to increase the amount of geometrically necessary dislocations (GNDs) within the material and, therefore, the amount of stored strain energy within the grains. The strain energy is then used during subsequent annealing to form coherent annealing twin boundaries via strain-induced grain boundary migration (SIBM). Additionally, the limits associated with recrystallization and the effect of grain growth were investigated to gather a significant amount of experimental results and derive constitutive models to describe the formation of twin boundaries in Ni-base superalloy RR1000. ${ }^{21,22}$ The models were used to predict the length fraction and density of $\Sigma 3$ boundaries as a function of the grain size following annealing and amount of deformation (or stored strain energy) following isothermal forging. Using the deformation mechanism map for RR1000 as a guide (Fig. 1), predictions from the developed models supported the concept that the isothermal forging parameters can be controlled to optimize the grain boundary character distribution of polycrystalline Ni-based superalloys.

\section{FATIGUE MODELING}

The ability to control the grain boundary character distribution and density of twin boundaries in polycrystalline Ni-base superalloys is significant as this can be exploited to further enhance the durability and performance of these materials. In recent years, a microstructure-explicit, physics-based fatigue model was developed and shown to be capable of identifying desirable microstructural features that contribute to enhancing the damage tolerance of RR1000. Similar to other high-strength polycrystalline Ni-base superalloys, fatigue crack nucleation and the overall fatigue life at low temperatures is largely dependent on the formation of persistent slip bands (PSBs), in which dislocations shear through the tertiary $\gamma^{\prime}$ precipitates thereby localizing strain. ${ }^{23}$ Constitutive models describing the formation and interaction of these PSBs with grain boundaries have been developed and implemented into a polycrystalline formulation that accounts for the effect of the neighboring microstructure. ${ }^{17,18,24}$ To assess the effect of microstructure and grain boundary character on the micro-mechanical strain fields that develop during deformation, a 3D crystal plasticity model was developed (Fig. 2). First, statistically equivalent 3D microstructures were created from 2D electron backscatter diffraction (EBSD) data. These synthetic microstructures consist of hundreds to thousands of discrete grains and are representative volume elements that possess characteristic features mimicking the texture, grain size distribution, and grain boundary content (including density of twins). Within the fatigue model, grain clusters are a primary location for fatigue crack initiation, whereas PSBs transmit through low-angle grain boundaries (LAGBs), defined by adjacent grains with $<15^{\circ}$ misorientations. ${ }^{23,24}$ As a result, the effective length of the PSB forms over the grain cluster leading to potential sites for fatigue crack initiation and an overall lower life. Annealing twins form within parent grains and offer a means to resist slip activity across the length of the parent grain. ${ }^{25}$ For this reason, the corresponding thermal-mechanical processing parameters used for forming of RR1000 forgings were optimized such that the density of coherent twin boundaries was maximized, via grain boundary engineering, which limits the potential PSB length and thereby prolongs fatigue failure.

\section{EXPERIMENTAL VALIDATION}

A series of small-scale forging trials were performed on RR1000 billets measuring $38 \mathrm{~mm}$ in diameter and of $38 \mathrm{~mm}$ height to validate the process models by producing a set of conventional and a separate set of grain boundary engineered microstructures. The conventional baseline microstructures were produced by forging the material at a temperature of $1100^{\circ} \mathrm{C}$ and a strain rate of $0.003 \mathrm{~s}^{-1}$, which are typical of deformation parameters for isothermal forging of power-processed 

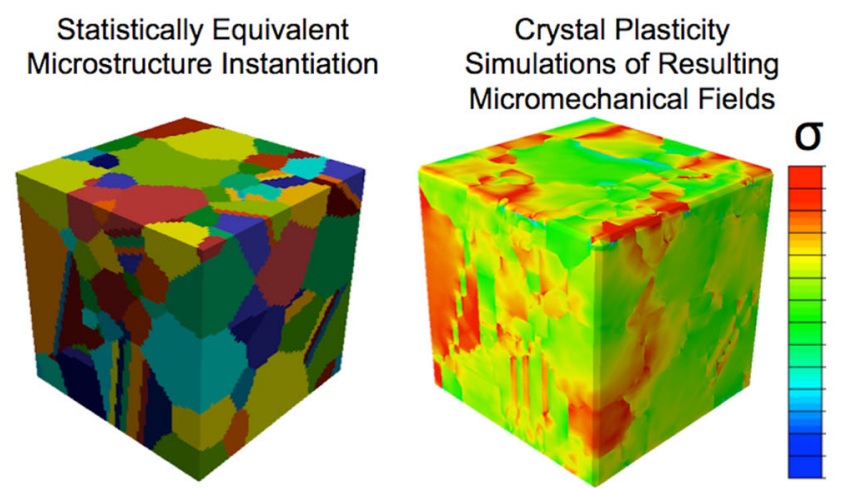

\section{Prediction of Location of Critical Persistent Slip Band Likely to Cause Failure}

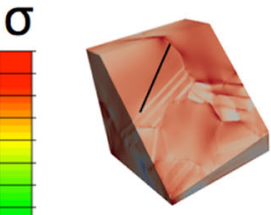

Plastic Strain Accumulation

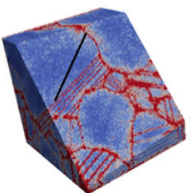

Elastic Stress Anisotropy

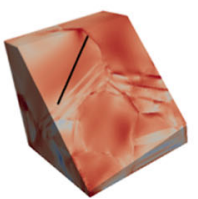

Resolved Shear Stress

Fig. 2. 3D crystal plasticity fatigue model for Ni-base superalloys showing the variation in stress and strain localization at various meso-scale features within the microstructure.
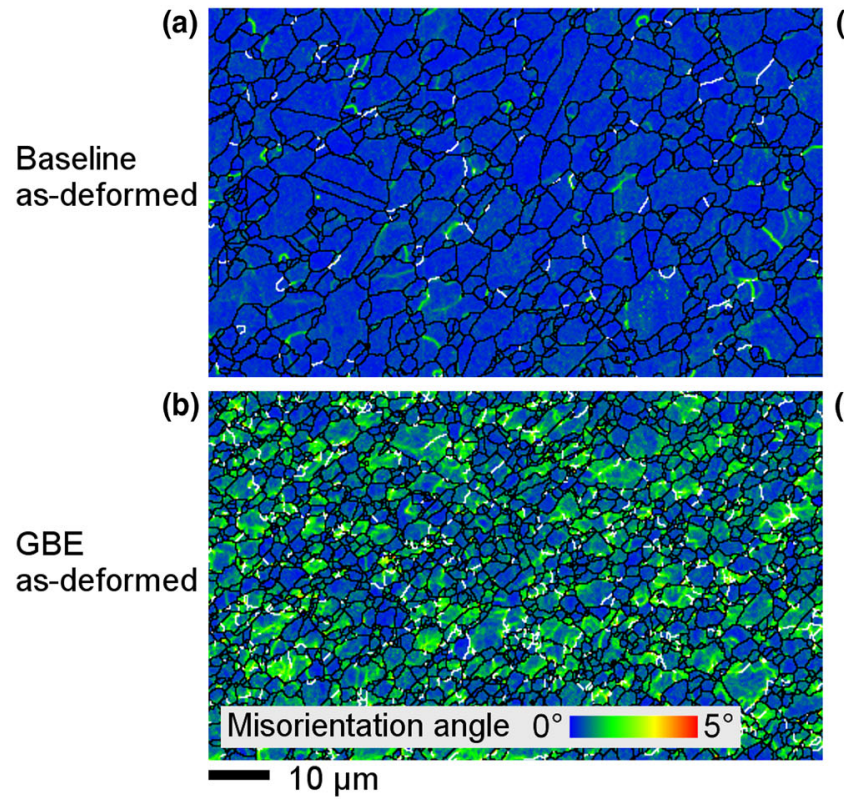

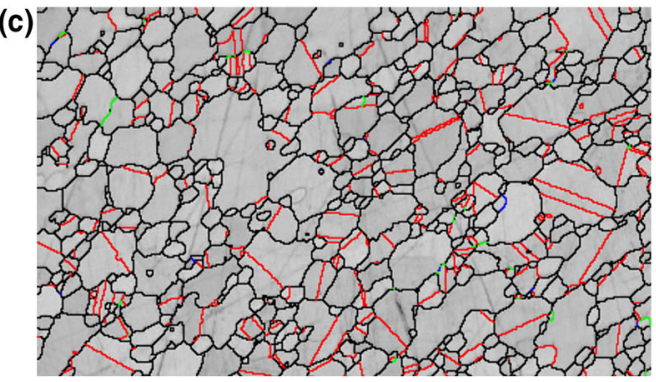

(d)

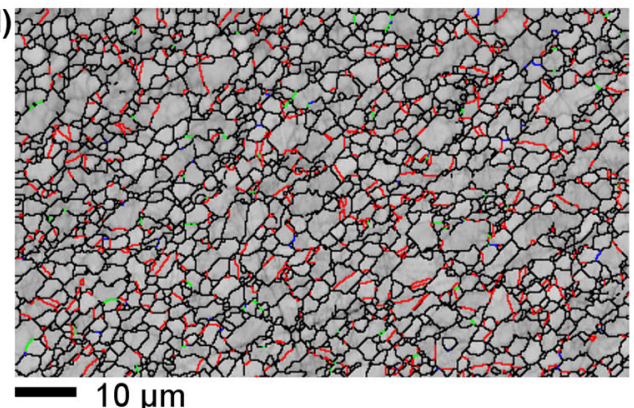

Fig. 3. (a, b) EBSD intragranular misorientation with low-angle boundaries $\left(5^{\circ} \leq\right.$ misorientation angle $\left.<15^{\circ}\right)$ in white and $(c$, d) grain boundary maps ( $\Sigma 3$ boundaries in red, $\Sigma 9$ in green, $\Sigma 27$ in blue, and random high-angle boundaries (misorientation angle $\geq 15^{\circ}$ ) in black) for the asdeformed $(a, c)$ baseline and (b, d) GBE forged billets (Color figure online).

superalloys. ${ }^{26}$ For comparison, a GBE microstructure was designed using the findings from the previous Process Modeling section, which resulted in a lower deformation temperature and a higher strain rate of $0.05 \mathrm{~s}^{-1}$, respectively. The billets were compressed to an effective strain of 0.75 to form 10 $\mathrm{mm}$-thick pancakes of $79 \mathrm{~mm}$ diameter. The asdeformed microstructures are shown using EBSD maps of the baseline and GBE material in Fig. 3. The intragranular misorientation maps are consistent with the process map of Fig. 1. The baseline asforged microstructure showed minimal intragranular misorientations and therefore negligible levels of GNDs (Fig. 3a). These results are consistent with deformation conditions corresponding to a dominant superplastic flow mechanism, while the as-forged GBE material exhibited considerable levels of GNDs or stored strain energy stemming from dislocationbased mechanisms being operative (Fig. $3 \mathrm{~b}$ ). This is supported by the decrease in grain size in the GBE material as compared to the baseline forging (Fig. 3c and d). Following deformation, the forgings were sectioned and subjected to either a sub-solvus or super-solvus annealing heat treatment with the super-solvus annealing being used to evaluate a coarse grain microstructure from the dissolution of the primary $\gamma^{\prime}$ precipitates. All processing conditions are referenced in Table I, but only the subsolvus condition, referred to as fine grain, will be discussed in this investigation. For more information about the coarse grain specimens, the reader is invited to refer to Ref. 22. The grain boundary maps for the sub-solvus annealed forgings are shown in Fig. 4 and revealed the promoted formation of $\Sigma 3$ 
Table I. Processing conditions for the four variants of RR1000, including isothermal forging condition (temperature and strain rate) and heat treatment

\begin{tabular}{lccc}
\hline & Conventionally forged (baseline) & & Grain boundary engineered (GBE) \\
\cline { 2 - 3 } Fine grain & Forged: $1100^{\circ} \mathrm{C}$ and $0.003 \mathrm{~s}^{-1}$ & & Forged: $1020^{\circ} \mathrm{C}$ and $0.05 \mathrm{~s}^{-1}$ \\
Coarse grain & Forged: $1100^{\circ} \mathrm{C}$ and $0.003 \mathrm{~s}^{-1}$ & & Sub-solvus annealed: $1115^{\circ} \mathrm{C}$ \\
& Super-solvus annealed: $1170^{\circ} \mathrm{C}$ following $1115^{\circ} \mathrm{C}$ & Super-solvus annealed: $1170^{\circ} \mathrm{C}$ following $1115^{\circ} \mathrm{C}$ \\
\hline
\end{tabular}

Each heat treatment was performed for $4 \mathrm{~h}$ with a controlled cooling rate of $1{ }^{\circ} \mathrm{C} / \mathrm{s}$.
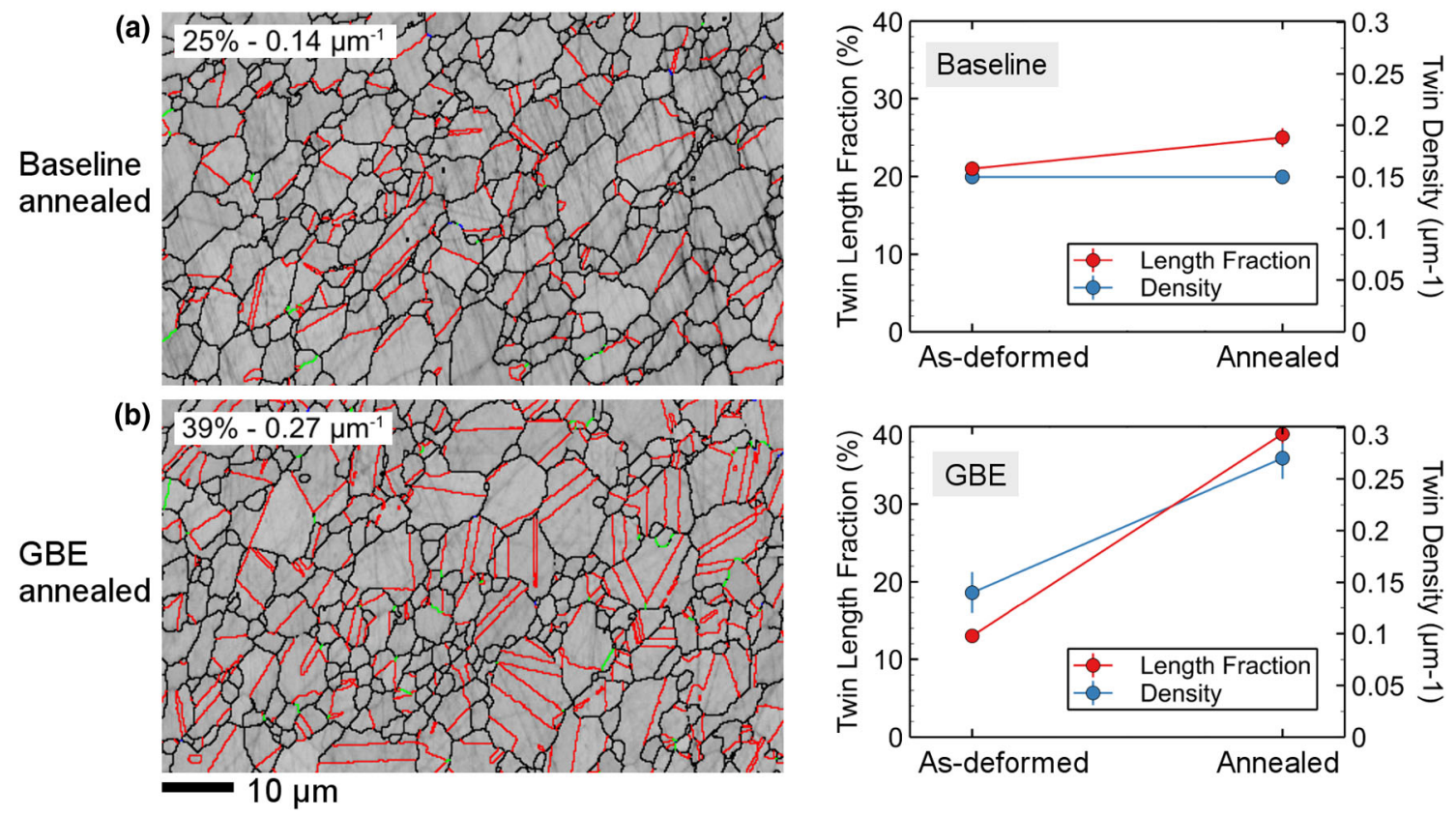

Fig. 4. Grain boundary maps of the (a) baseline and (b) GBE billets following annealing with $\Sigma 3$ boundaries represented in red, $\Sigma 9$ in green, $\Sigma 27$ in blue, and random high-angle boundaries in black and with relative plots showing the evolution of the twin density and length fraction from asdeformed to annealed for each processing route.

boundaries following the GBE processing route (Fig. 4b). Image analysis revealed no change in twin density from as-deformed to annealed condition of the baseline material and only a slight increase in the twin length fraction, which was likely attributed to the change in grain size. Conversely, the GBE forging showed a significant increase in both twin density and length fraction from the as-deformed to annealed condition with a twin density nearly twice that of the baseline forging following annealing. Thus, the results from forging trials validated the process models, and a grain boundary engineered microstructure was successfully produced.

\section{FATIGUE SIMULATIONS}

The four variant microstructures produced in this study were analyzed for attributes of grain size, orientation, and boundary distributions. From the statistical characterization of these microstructures, ten virtual instantiations of each microstructure were produced, which are used to provide critical information regarding the affect of microstructure variability on fatigue scatter. These microstructures were used to initialize a crystal plasticity finite element simulation, in order to calculate the micromechanical fields relative to the microstructure. From the microstructural and micromechanical information of each instantiation, we deployed a fatigue model that determines the energy of potential PSBs on a grain-by-grain basis and their evolution with respect to cyclic loading. Crack initiation is achieved when the PSB reaches a minimum, stable energy, representing the weakest link in the material. A cycles-to-crack initiation is determined for each microstructure instantiation, the results of which are shown in Fig. 5, in terms of a probability to failure for the fine grain (sub-solvus) 


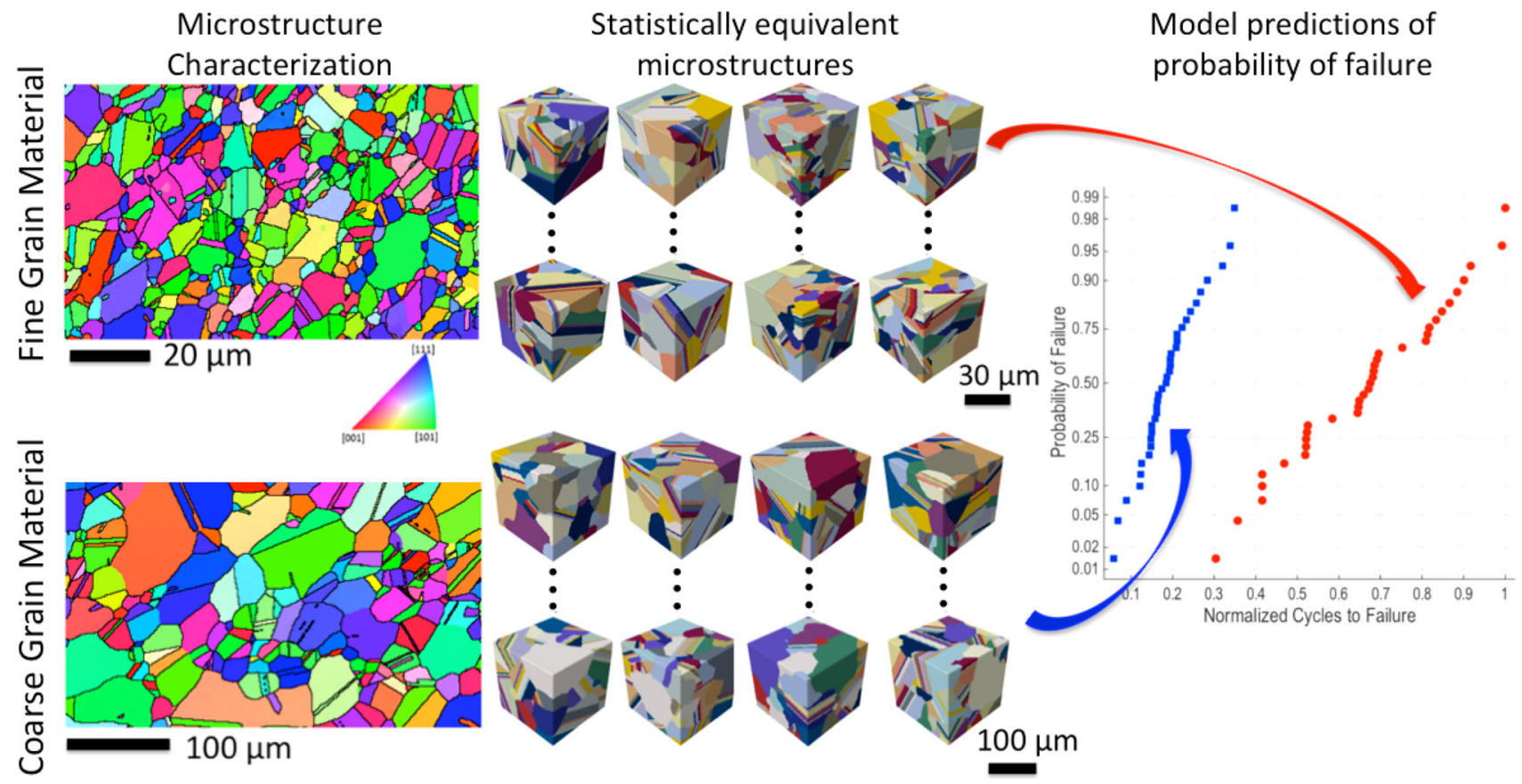

Fig. 5. Application of the 3D crystal plasticity fatigue model to predict the performance of RR1000 as a function of microstructure.

and coarse grain (super-solvus) conditions. The subsolvus material displays improved resistance to fatigue crack initiation, due to its fine grain structure thereby preventing the formation of long PSBs. For this reason, we focus on experiential analysis of the fine grain microstructure in the following section.

\section{STRAIN MAPPING}

High-resolution digital image correlation (DIC) was performed on the two variants of the sub-solvus RR1000 material to identify heterogeneous deformation. Furthermore, consolidating the strain map, obtained via DIC, with the GB information from EBSD, provided a quantifiable view of strain localization relative to microstructural features. Dog bone specimens were extracted from the small scale forgings, in which the specimen gauge section measured $10 \mathrm{~mm} \times 3 \mathrm{~mm}$ with a thickness of $1.25 \mathrm{~mm}$. Each specimen was subjected to a load necessary to achieve $1 \%$ total strain and then unloaded. At zero load, the specimens were subjected to ex situ imaging within a scanning electron microscope. These images were used to conduct DIC measurements. Additional information about the DIC methodology, image capturing, and distortion correction protocols are provided in Ref. 27. Afterward, the specimens were cycled in load control (with a load corresponding to the maximum load recorded during the first cycle) with an $R$ ratio of 0.1 . At 10, 100, and 1000 cycles, the specimen was removed from the load frame to conduct DIC characterization, producing the results shown in
Fig. 6. The DIC results of the GBE specimen displayed a poor correlation at 1000 cycles, due to excessive out-of-plane deformation, and thus is not shown in Fig. 6. Both microstructure variants were seen to form macroscopic bands of strain with orientation of $45^{\circ}$ relative to the loading axis.

As shown in Fig. 6, individual slip bands are observable in the DIC strain maps. The resolution was not sufficient to capture individual slip bands within smaller grains. It should be noted that the measured grain size was modestly larger for the baseline material, and thus more slip bands were observed. The GBE material provides an increased propensity of twin boundaries, which impedes slip within a parent grain, causing each twin variant within the parent grain to behave as several smaller grains. With each twin boundary providing slip impedance, the overall length of each slip band is reduced. This result is in agreement with past measurements of slip band length in coarse grain RR1000 materials. ${ }^{22}$ Moreover, these observations are consistent with the fatigue modeling results, whereas the formation of longer PSBs represented a higher degree of stored energy and were attributed to a shorter fatigue life. ${ }^{22}$

Lastly, fatigue crack initiation has been observed extensively throughout the years at or near twin boundaries, stemming back to the work of Boettner et al. $^{28}$ and Thompson ${ }^{29}$ and more recently in $\mathrm{Ni}$ based superalloys. ${ }^{24,30,31}$ Moreover, there exists a high prevalence of annealing twin boundaries inherent to Ni-based superalloys, such that the majority of cracks initiate due to twin boundaries. In the current approach, GBE increases the density 

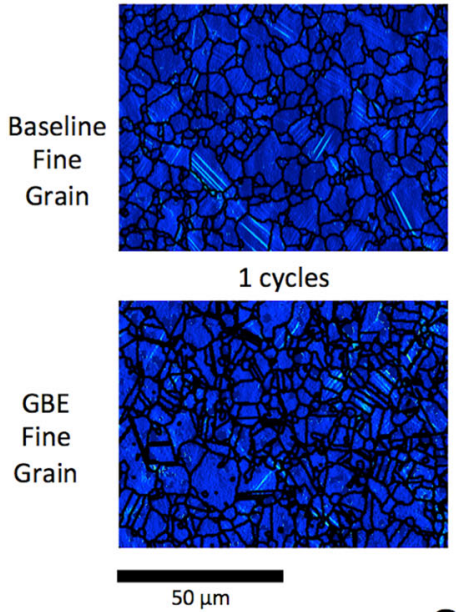

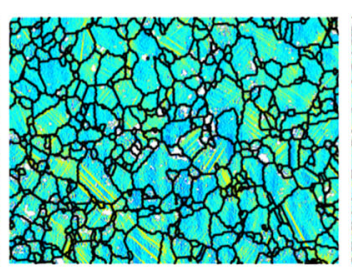

10 cycles

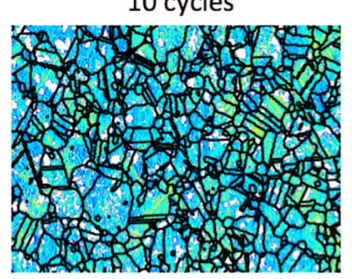

0

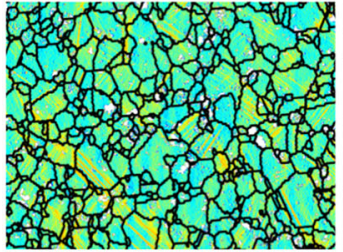

100 cycles

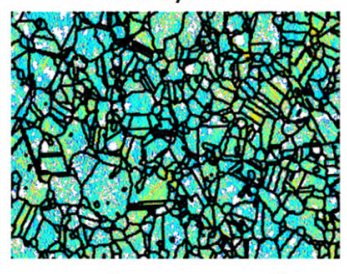

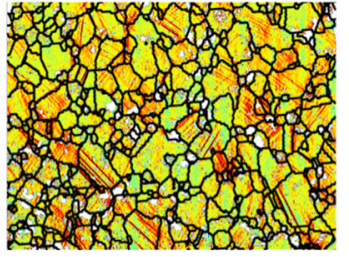

1000 cycles

$\varepsilon_{\mathrm{xx}}(\%)$

Fig. 6. Axial direction, $\varepsilon_{x x}$, strain maps of an area of interest $(200 \mu \mathrm{m} \times 200 \mu \mathrm{m})$ in the Baseline (top row) and GBE (bottom row) fine grain material. Deformation maps shown at 1, 10,100, and 1000 fatigue cycles. Areas colored white have a low confidence index and were removed from analysis.

of twin boundaries, thereby restricting the length of slip band formation. The reduced slip band length, analogous to the reduced length of the twin boundary, ${ }^{31}$ is associated with improved fatigue life. Thus, while the increased density of twin boundaries act as additional sites for crack initiation, they also reduce the formation of long slip bands and thereby act to reduce strain localization by dispersing deformation throughout the microstructure. Therefore, while twins act as potential sites for crack initiation, the GBE approach still offers a strategy to improve the overall fatigue resistance of the material.

\section{CONCLUSION}

In summary, an integrated computational materials engineering framework was adopted to design damage-tolerant microstructures in a commercial Ni-base superalloy, RR1000, by manipulating the grain boundary character distributions. Process models and deformation mechanism maps for thermal-mechanical processing of RR1000 were developed to enable tailoring and improved control of grain boundary character distributions following forming operations. The ability to control the grain boundary character distribution and twin density in polycrystalline materials is significant as this can potentially be exploited to improve the susceptibility to fatigue failures. Optimization and engineering of the microstructure for RR1000 was guided using a 3D crystal plasticity finite element fatigue crack nucleation model, originating from persistent slip bands (PSBs). Simulations from the model were used to elucidate the key microstructural features associated with enhanced fatigue lives. Since the overall length of PSBs correlates strongly with the degree of strain localization, the local neighboring grain structure, in terms of both the grain boundary characters and grain sizes, affects the fatigue performance. This knowledge was used to inform the design of a modified isothermal forming process for producing fine-grained RR1000 with a high density of coherent twin boundaries. Experimental validation was completed using small-scale forgings of conventionally processed and grain boundary engineered (GBE) RR1000. Following a postforging sub-solvus heat treatment, the density of twin boundaries in the GBE sample was almost doubled in comparison to the conventionally processed RR1000 forging. Differences in the heterogeneous strain distribution in the conventional and GBE RR1000 samples were captured in the high-resolution DIC strain maps. In both instances, macroscopic bands were oriented $45^{\circ}$ relative to the loading direction and twin boundaries were noted to be effective microstructural features for impeding slip.

\section{ACKNOWLEDGEMENTS}

Financial support for this work was provided by the National Science Foundation (Grant Number CMMI 13-34664 and 13-34998) and the Rolls-Royce Corporation. The authors would like to thank Mark Hardy from Rolls-Royce plc; Randy Helmink, Robert Goetz, and Eugene Sun of Rolls-Royce Corporation for useful discussions about this work; and Saikumar Yeratapally for assistance with the simulations.

\section{REFERENCES}

1. J.C. Williams and E.A. Starke Jr., Acta Mater. 51, 5775 (2003).

2. F.C. Campbell Jr., Manufacturing Technology for Aerospace Structural Materials (New York: Elsevier, 2011).

3. B.A. Cowles, Int. J. Fract. 80, 147 (1996).

4. J.M. Larsen, B.D. Worth, C.G. Annis, and F.K. Haake, Int. J. Fract. 80, 237 (1996). 
5. J. Hou, B.J. Wicks, and R.A. Antoniou, Eng. Failure Anal. 9, 201 (2002)

6. T.M. Pollock and S. Tin, J. Prop. Power 22, 361 (2006).

7. R.C. Reed, The Superalloys: Fundamentals and Applications (Cambridge: Cambridge University Press, 2008).

8. R.W. Kozar, A. Suzuki, W.W. Milligan, J.J. Schirra, M.F. Savage, and T.M. Pollock, Metall. Mater. Trans. A 40, 1588 (2009).

9. D.G. Backman, D.Y. Wei, D.D. Whitis, M.B. Buczek, P.M. Finnigan, and D. Gao, JOM 58 (11), 36 (2006).

10. J. Gong, D. Snyder, T. Kozmel, C. Kern, J.E. Saal, I. Berglund, J. Sebastian, and G. Olson, JOM 69 (5), 880 (2017).

11. G.B. Olson, H. J. Jou, J. Jung, J. T. Sebastian, A. Misra, I Locci, and D. Hull, in 11th International Symposium on Superalloys, Superalloys (2008).

12. J. Allison, JOM 63 (4), 15 (2011).

13. A. Kermanpur, P.D. Lee, M. McLean, and S. Tin, JOM 56 (3), 72 (2004).

14. S. Tin, P.D. Lee, A. Kermanpur, M. McLean, and M. Rist, Metall. Mater. Trans. A 36, 2493 (2005).

15. S.R. Yeratapally, S.R.M.G. Glavicic, M. Hardy, and M.D. Sangid, Acta Mater. 107, 152 (2016).

16. S.R. Yeratapally, M.G. Glavicic, C. Argyrakis, and M.D. Sangid, Reliab. Eng. Syst. Saf. 164, 110 (2017).

17. G. Palumbo, P. Lehockey, and P. Lin, JOM 50 (2), 40 (1998).

18. V. Randle, Acta Mater. 52, 4067 (2004).
19. C.A. Schuh, M. Kumar, and W.E. King, Acta Mater. 51, 687 (2003).

20. M. Detrois, J. Rotella, R.L. Goetz, R.C. Helmink, and S. Tin, Mater. Sci. Eng., A 627, 95 (2015).

21. M. Detrois, R.L. Goetz, R.C. Helmink, and S. Tin, Mater. Sci. Eng., A 647, 157 (2015).

22. M. Detrois, J. Rotella, M. Hardy, S. Tin, and M.D. Sangid, Integr. Mater. Manuf. Innov. 6, 265 (2017).

23. M.D. Sangid, Int. J. Fatigue 57, 58 (2017).

24. M.D. Sangid, H.J. Maier, and H. Sehitoglu, Int. J. Plast. 27, 801 (2011)

25. M.D. Sangid, T. Ezaz, H. Sehitoglu, and I.M. Robertson, Acta Mater. 59, 283 (2011).

26. I.M.D. Parr, T. J. Jackson, M. C. Hardy, D. J. Child, C. Argyrakis, K. Severs, V. Saraf, and J. M. Stumpf, in Superalloys 2016: Proceedings of the 13th Intenational Symposium of Superalloys (New York: Wiley, 2016), pp. 447-456.

27. A.W. Mello, T.A. Book, A. Nicolas, S.E. Otto, C.J. Gilpin, and M.D. Sangid, Exper. Mech. 57, 1395 (2017).

28. R.C. Boettner, J.A.J. McEvily, and Y.C. Liu, Phil. Mag. 10, 95 (1964).

29. A.W. Thompson, Acta Metall. 20, 1085 (1972).

30. J. Miao, T.M. Pollock, and J. Wayne, Jones. Acta Mater. 57, 5964 (2009).

31. J.C. Stinville, W.C. Lenthe, J. Miao, and T.M. Pollock, Acta Mater. 103, 461 (2016). 